\title{
Low-temperature growth of low friction wear- resistant amorphous carbon nitride thin films by mid-frequency, high power impulse, and direct current magnetron sputtering
}

\author{
Konstantinos D. Bakoglidis, Susann Schmidt, Magnus Garbrecht, Ivan G. Ivanov, \\ Jens Jensen, Grzegorz Greczynski and Lars Hultman
}

\section{Linköping University Post Print}

\section{Tweet}

N.B.: When citing this work, cite the original article.

Original Publication:

Konstantinos D. Bakoglidis, Susann Schmidt, Magnus Garbrecht, Ivan G. Ivanov, Jens Jensen, Grzegorz Greczynski and Lars Hultman, Low-temperature growth of low friction wear-resistant amorphous carbon nitride thin films by mid-frequency, high power impulse, and direct current magnetron sputtering, Journal of Vacuum Science \& Technology. A, 2015, 33(5), 05E112

http://dx.doi.org/10.1116/1.4923275

Copyright: American Vacuum Society http://www.avs.org/

Postprint available at: Linköping University Electronic Press http://urn.kb.se/resolve?urn=urn:nbn:se:liu:diva-118343 


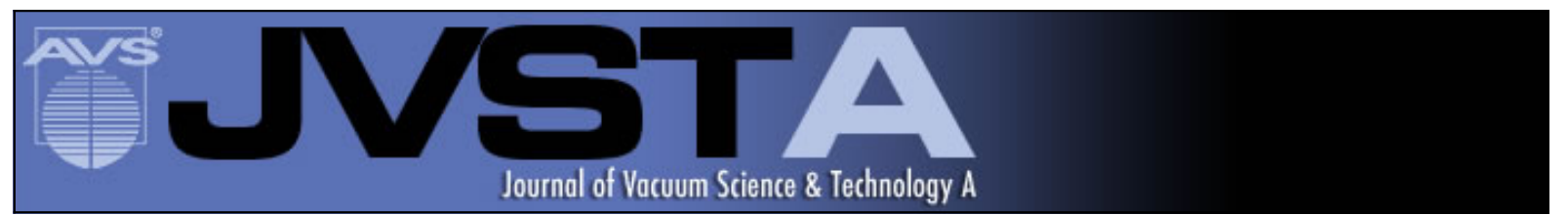

Low-temperature growth of low friction wear-resistant amorphous carbon nitride thin films by mid-frequency, high power impulse, and direct current magnetron sputtering

Konstantinos D. Bakoglidis, Susann Schmidt, Magnus Garbrecht, Ivan G. Ivanov, Jens Jensen, Grzegorz

Greczynski, and Lars Hultman

Citation: Journal of Vacuum Science \& Technology A 33, 05E112 (2015); doi: 10.1116/1.4923275

View online: http://dx.doi.org/10.1116/1.4923275

View Table of Contents: http://scitation.aip.org/content/avs/journal/jvsta/33/5?ver=pdfcov

Published by the AVS: Science \& Technology of Materials, Interfaces, and Processing

\section{Articles you may be interested in}

Strength, stiffness, and microstructure of $\mathrm{Cu}(\mathrm{In}, \mathrm{Ga}) \mathrm{Se} 2$ thin films deposited via sputtering and co-evaporation Appl. Phys. Lett. 105, 011907 (2014); 10.1063/1.4890086

Reactive sputtering of $\delta-\mathrm{ZrH} 2$ thin films by high power impulse magnetron sputtering and direct current magnetron sputtering

J. Vac. Sci. Technol. A 32, 041510 (2014); 10.1116/1.4882859

Physical properties of epitaxial $\mathrm{ZrN} / \mathrm{MgO}(001)$ layers grown by reactive magnetron sputtering

J. Vac. Sci. Technol. A 31, 061516 (2013); 10.1116/1.4825349

Correlation of structure and hardness of rf magnetron sputtered silicon carbonitride films

J. Vac. Sci. Technol. A 28, 505 (2010); 10.1116/1.3420430

Growth of fullerene-like carbon nitride thin solid films by reactive magnetron sputtering; role of low-energy ion irradiation in determining microstructure and mechanical properties

J. Appl. Phys. 93, 3002 (2003); 10.1063/1.1538316

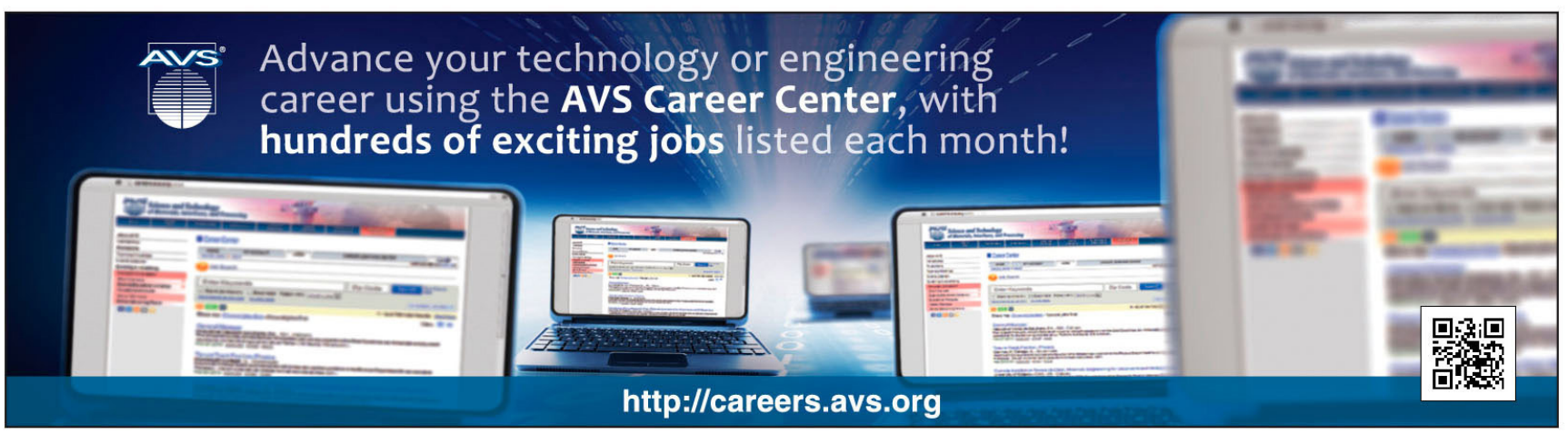




\title{
Low-temperature growth of low friction wear-resistant amorphous carbon nitride thin films by mid-frequency, high power impulse, and direct current magnetron sputtering
}

\author{
Konstantinos D. Bakoglidis, ${ }^{\text {a) }}$ Susann Schmidt, Magnus Garbrecht, Ivan G. Ivanov, \\ Jens Jensen, Grzegorz Greczynski, and Lars Hultman \\ Department of Physics, Chemistry and Biology (IFM), Linköping University, SE-581 83 Linköping, Sweden
}

(Received 24 April 2015; accepted 18 June 2015; published 26 June 2015)

\begin{abstract}
The potential of different magnetron sputtering techniques for the synthesis of low friction and wear resistant amorphous carbon nitride $\left(\mathrm{a}-\mathrm{CN}_{\mathrm{x}}\right)$ thin films onto temperature-sensitive AISI52100 bearing steel, but also $\mathrm{Si}(001)$ substrates was studied. Hence, a substrate temperature of $150^{\circ} \mathrm{C}$ was chosen for the film synthesis. The a- $\mathrm{CN}_{\mathrm{x}}$ films were deposited using mid-frequency magnetron sputtering (MFMS) with an MF bias voltage, high power impulse magnetron sputtering (HiPIMS) with a synchronized HiPIMS bias voltage, and direct current magnetron sputtering (DCMS) with a DC bias voltage. The films were deposited using a $\mathrm{N}_{2} / \mathrm{Ar}$ flow ratio of 0.16 at the total pressure of $400 \mathrm{mPa}$. The negative bias voltage, $\mathrm{V}_{\mathrm{s}}$, was varied from 20 to $120 \mathrm{~V}$ in each of the three deposition modes. The microstructure of the films was characterized by high-resolution transmission electron microscopy and selected area electron diffraction, while the film morphology was investigated by scanning electron microscopy. All films possessed an amorphous microstructure, while the film morphology changed with the bias voltage. Layers grown applying the lowest substrate bias of $20 \mathrm{~V}$ exhibited pronounced intercolumnar porosity, independent of the sputter technique. Voids closed and dense films are formed at $\mathrm{V}_{\mathrm{s}} \geq 60 \mathrm{~V}, \mathrm{~V}_{\mathrm{s}} \geq 100 \mathrm{~V}$, and $\mathrm{V}_{\mathrm{s}}=120 \mathrm{~V}$ for MFMS, DCMS, and HiPIMS, respectively. X-ray photoelectron spectroscopy revealed that the nitrogen-to-carbon ratio, $N / C$, of the films ranged between 0.2 and 0.24 . Elastic recoil detection analysis showed that $\mathrm{Ar}$ content varied between 0 and 0.8 at. $\%$ and increased as a function of $\mathrm{V}_{\mathrm{s}}$ for all deposition techniques. All films exhibited compressive residual stress, $\sigma$, which depends on the growth method; HiPIMS produces the least stressed films with values ranging between -0.4 and $-1.2 \mathrm{GPa}$ for all $\mathrm{V}_{\mathrm{s}}$, while $\mathrm{CN}_{\mathrm{x}}$ films deposited by MFMS showed residual stresses up to $-4.2 \mathrm{GPa}$. Nanoindentation showed a significant increase in film hardness and reduced elastic modulus with increasing $\mathrm{V}_{\mathrm{s}}$ for all techniques. The harder films were produced by MFMS with hardness as high as $25 \mathrm{GPa}$. Low friction coefficients, between 0.05 and 0.06 , were recorded for all films. Furthermore, $\mathrm{CN}_{\mathrm{x}}$ films produced by MFMS and DCMS at $\mathrm{V}_{\mathrm{s}}=100$ and $120 \mathrm{~V}$ presented a high wear resistance with wear coefficients of $k \leq 2.3 \times$ $10^{-5} \mathrm{~mm}^{3} / \mathrm{Nm}$. While all $\mathrm{CN}_{\mathrm{x}}$ films exhibit low friction, wear depends strongly on the structural and mechanical characteristics of the films. The MFMS mode is best suited for the production of hard $\mathrm{CN}_{\mathrm{x}}$ films, although high compressive stresses challenge the application on steel substrates. Films grown in HiPIMS mode provide adequate adhesion due to low residual stress values, at the expense of lower film hardness. Thus, a relatively wide mechanical property envelope is presented for $\mathrm{CN}_{\mathrm{x}}$ films, which is relevant for the optimization of $\mathrm{CN}_{\mathrm{x}}$ film properties intended to be applied as low friction and wear resistant coatings. (c) 2015 American Vacuum Society.
\end{abstract}

[http://dx.doi.org/10.1116/1.4923275]

\section{INTRODUCTION}

Carbon nitride $\left(\mathrm{CN}_{\mathrm{x}}\right)$ compounds are used extensively as protective coatings in disk drives and for biomedical applications. ${ }^{1-3}$ Their attractive mechanical and tribological properties arise from a structural and bonding complexity induced by the substitution of carbon for nitrogen. $\mathrm{CN}_{\mathrm{x}}$ films may exhibit short-range order (SRO), which is defined by a complex interplay of the $s p^{3}, s p^{2}$, and $s p$ hybridized bonds that carbon and nitrogen can form. Depending on the deposition parameters, a variety of $\mathrm{CN}_{\mathrm{x}}$ microstructures can be formed during

${ }^{a}$ Electronic mail: konba@ifm.liu.se thin film synthesis, including amorphous $\left(\mathrm{a}-\mathrm{CN}_{\mathrm{x}}\right),{ }^{4}$ graphitelike $\left(\mathrm{g}-\mathrm{CN}_{\mathrm{x}}\right),{ }^{5}$ and fullerene-like carbon nitride $\left(\mathrm{FL}-\mathrm{CN}_{\mathrm{x}}\right){ }^{6,7}$

Hard, yet elastic $\mathrm{CN}_{\mathrm{x}}$ films have been reported to form at elevated temperatures $\left(>350^{\circ} \mathrm{C}\right)$, low to medium particle energies, using a wide range of $\mathrm{N}_{2} / \mathrm{Ar}$ flow ratios by both direct current magnetron sputtering (DCMS) and high power impulse magnetron sputtering (HiPIMS). ${ }^{6,8}$ At such deposition conditions, a distinct FL structural evolution with bent, cross-linked graphene sheets forms with primarily $s p^{2}$ bonding. ${ }^{10,11}$ Low-density a-CN $\mathrm{CN}_{\mathrm{x}}$ films are generally produced at low growth temperatures. Depending on process settings other than the substrate temperature, a variety of film morphologies, ranging from columnar with voids to homogeneous closepacked, are observed. ${ }^{8,12}$ For substrate temperatures $<200^{\circ} \mathrm{C}$, 
the $\mathrm{N}$ fraction in the plasma does not affect the film microstructure, since the chemical sputtering phenomena that have been found to influence the structure of the films ${ }^{8}$ are not as distinct. Thus, increasing the substrate temperature yields films that exhibit FL-phase. ${ }^{8}$ However, deposition temperatures above $200^{\circ} \mathrm{C}$ are intolerable for several important industrial applications employing temperature-sensitive substrates. ${ }^{13}$

A large amount of studies are dedicated to the bonding of $\mathrm{N}$ in the $\mathrm{C}$ matrix. ${ }^{14-16}$ The microstructure of a-CN $\mathrm{CN}_{\mathrm{x}}$ is a network of $s p^{2}$ and $s p^{3}$ hybridized states of $\mathrm{C}$ and N. Ratios between $s p^{3}$ and $s p^{2}$ bonding states may vary for a- $\mathrm{CN}_{\mathrm{x}}$ deposited under different conditions. For instance, different $s p^{3} / s p^{2}$ ratios were found to determine the mechanical and tribological properties of a- $\mathrm{CN}_{\mathrm{x}}$ films deposited by radio frequency magnetron sputtering (RFMS) with increasing substrate bias. ${ }^{17}$ Moreover, the predominant amount of $s p^{2}$ hybridized states of $\mathrm{CN}_{\mathrm{x}}$ films enhances their elasticity, mechanical resiliency, and wear resistance, ${ }^{12,18}$ which are critical properties for sliding or rolling components.

Several magnetron-sputtering-based techniques have been used to grow a- $\mathrm{CN}_{\mathrm{x}}$ thin films, among them are DCMS,${ }^{8,12}$ RFMS, ${ }^{19-21}$ and HiPIMS. ${ }^{9,22}$ Depending on the growth conditions, a broad range of hardness and elastic modulus values for $\mathrm{CN}_{\mathrm{x}}$ films can be found in the literature. Hardness values approaching those of the basically $s p^{3}$-rich tetrahedral amorphous carbon (ta-C) or diamond-like carbon (DLC) films ${ }^{20,23-26}$ were reported. Different deposition techniques also affect the tribological performance of $\mathrm{CN}_{\mathrm{x}}$ films. Low friction coefficients and low wear rates have been recorded for a-CN $\mathrm{CN}_{\mathrm{x}}$ films applying different loads, speeds, ${ }^{25}$ and gas environments. ${ }^{27}$

Today, the effects of different growth parameters on $\mathrm{CN}_{\mathrm{x}}$ properties are relatively understood for DCMS and RFMS processes. The plasma characteristics influencing growth conditions of $\mathrm{CN}_{\mathrm{x}}$ films deposited by HiPIMS were studied more recently, ${ }^{9}$ while knowledge on the influences of some parameters of HiPIMS in the $\mathrm{CN}_{\mathrm{x}}$ growth remains limited. To the best of our knowledge, growth of $\mathrm{CN}_{\mathrm{x}}$ films using mid-frequency magnetron sputtering (MFMS) has not been reported yet, although MFMS can be used to investigate a further customization of the structural and mechanical properties of $\mathrm{CN}_{\mathrm{x}}$ films. Thus, it is timely to make a comparative study of the structural and mechanical properties of $\mathrm{CN}_{\mathrm{x}}$ films, grown by various sputtering methods, applied under similar growth conditions at low substrate temperature.

In this study, properties of low temperature $\mathrm{CN}_{\mathrm{x}}$ films grown in one industrial deposition system using MFMS, HiPIMS, or DCMS are compared. Growth conditions, specifically gas composition, total gas pressure, substrate temperature, and average cathode power were kept constant for all depositions, facilitating a direct comparison of results. For each of the methods, a series of films are grown as a function of the negative substrate bias, $\mathrm{V}_{\mathrm{s}}$. Bonding type and composition of the $\mathrm{CN}_{\mathrm{x}}$ films, as well as the amount and role of incorporated impurities, such as $\mathrm{Ar}$ and $\mathrm{O}$, are discussed. Furthermore, we compare the nanomechanical properties and the nanotribological performance of the films and relate these properties to their structural characteristics and to the corresponding deposition conditions.

\section{EXPERIMENT}

$\mathrm{Si}(001)$ and steel substrates (grade AISI52100) were used for the deposition of $\mathrm{CN}_{\mathrm{x}}$ thin films. The steel grade AISI52100 is commonly used in bearing applications. The choice of steel substrates permits investigations as for the applicability of the $\mathrm{CN}_{\mathrm{x}}$ films on rolling and sliding components. $\mathrm{Si}(001)$ substrates, on the other hand, were selected as these suit a wide variety of characterization techniques. The cleaning of the steel substrates prior to the depositions was a three-step procedure: (1) a decon-90 (Decon Laboratories Limited, England) ultrasonic bath, (2) a $10 \mathrm{~min}$ acetone (Merck KGaA, Germany) ultrasonic bath, and (3) an isopropanol rinse (Merck KGaA, Germany). The substrates were subsequently dried in $\mathrm{N}_{2}$. The cleaning of the conventional boron doped $\mathrm{Si}(001)$ substrates included only steps (2) and (3).

An industrial deposition chamber (CC800/9 ML, CemeCon AG, Germany) was used to grow $\mathrm{CN}_{\mathrm{x}}$ thin films on the aforementioned $\mathrm{Si}$ and steel substrates. A schematic of the deposition chamber configuration is presented in Fig. 1. A hollow cathode etching step of 25 min was performed in order to clean the substrates prior to $\mathrm{CN}_{\mathrm{x}}$ deposition. Here, a $\mathrm{Kr} / \mathrm{Ar}$ gas mixture with a $\mathrm{Kr} / \mathrm{Ar}$ flow ratio of 0.76 , at a total pressure of $600 \mathrm{mPa}$, a temperature of $150^{\circ} \mathrm{C}$, and negative substrate bias of $200 \mathrm{~V}$ was applied. For the $\mathrm{CN}_{\mathrm{x}}$ depositions, two rectangular graphite targets with a size of $8.8 \times 50 \mathrm{~cm}^{2}$ were mounted on planar cathodes. The substrates were onefold rotated, with a rotation speed of $1 \mathrm{rpm}$. The depositions were conducted with a $\mathrm{N}_{2} / \mathrm{Ar}$ flow ratio of 0.16 and a total pressure of $400 \mathrm{mPa}$. The substrate temperature was kept at $\sim 150^{\circ} \mathrm{C}$ throughout the deposition. $\mathrm{CN}_{\mathrm{x}}$ films were deposited by MFMS, HiPIMS, and DCMS with an average target power of $1200 \mathrm{~W}$.

In MFMS configuration, one target operates as cathode while the other works as an anode, changing their polarity every half a cycle. In this case, the targets were operated at frequency $f=50 \mathrm{kHz}$, with a pulse length (pulse-on time) of $t_{\mathrm{on}}^{\mathrm{MF}_{\mathrm{tar}}}=10 \mu \mathrm{s}$ and a pulse-off time of $t_{\mathrm{off}}^{\mathrm{MF}_{\mathrm{tar}}}=10 \mu \mathrm{s}$. The

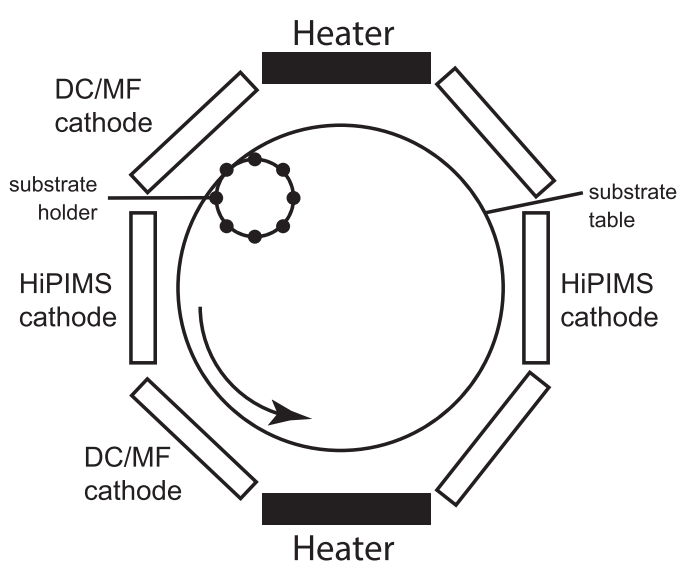

FIG. 1. Schematic top view of the industrial deposition chamber CC800/9 ML from CemeCon AG. 
average target current during the MFMS process was $I_{\mathrm{ave}}^{\mathrm{MF}} \sim$ $2.65 \mathrm{~A}$, and the target voltage averaged $V_{\text {ave }}^{\mathrm{MF}} \sim 452 \mathrm{~V}$. During DCMS processes, the average target current was $I_{\text {ave }}^{\mathrm{DC}} \sim 2.5 \mathrm{~A}$ and the average target voltage $V_{\text {ave }}^{\mathrm{DC}} \sim 480 \mathrm{~V}$. The HiPIMS processes featured a pulse frequency of $300 \mathrm{~Hz}$, pulse lengths of $t_{\mathrm{on}}^{\mathrm{Hi} \mathrm{P}_{\mathrm{tar}}}=200 \mu \mathrm{s}$, with $t_{\mathrm{off}}^{\mathrm{HiP}}=3.1 \mathrm{~ms}$, resulting in a pulse energy of $E_{p} \sim 4 \mathrm{~J}$, with peak target current $I_{p}^{\mathrm{HiP}} \sim 80 \mathrm{~A}$ and peak target voltage $V_{p}^{\mathrm{HiP}} \sim 700 \mathrm{~V}$. During HiPIMS processes, the average target current was $I_{\mathrm{ave}}^{\mathrm{HiP}} \sim 2 \mathrm{~A}$ with an average target voltage of $V_{\text {ave }}^{\text {HiP }} \sim 600 \mathrm{~V}$.

Negative substrate bias voltages, $\mathrm{V}_{\mathrm{s}}$, with amplitudes of $20,60,100$, and $120 \mathrm{~V}$ were applied during films growth. For MFMS depositions, $\mathrm{V}_{\mathrm{s}}$ was pulsed and not synchronized to the cathode operation using $t_{\mathrm{on}}^{\mathrm{MF} \text { bias }}=2.2 \mu \mathrm{s}$ and $t_{\mathrm{off}}^{\mathrm{MF} \text { bias }}=2.8 \mu \mathrm{s}$. During HiPIMS processes, the bias voltage supply was pulsed and synchronized to the cathode pulses, with $t_{\mathrm{on}}^{\mathrm{Hi} \text { bias }_{\text {ias }}}=200 \mu \mathrm{s}$ and $t_{\text {off }}^{\mathrm{Hi} \text { bias }}=3.1 \mathrm{~ms}$. DC bias voltages were applied during DCMS. Hence, the substrate bias duty cycles, D, were 44\%, $6 \%$, and $100 \%$ for MFMS, HiPIMS, and DCMS, respectively. The deposition times were adjusted to result in $\mathrm{CN}_{\mathrm{x}}$ film thickness of $1 \pm 0.2 \mu \mathrm{m}$.

Cross-sectional high-resolution transmission electron microscopy (HRTEM) images and selected area electron diffraction (SAED) patterns were acquired with a double corrected and monochromated FEI $\operatorname{Titan}^{3}$ 60-300 TEM, equipped with a high-brightness extreme field emission gun source. The energy of the electron beam for the TEM imaging and SAED acquisition was set to $300 \mathrm{keV}$, for optimum image contrast. The TEM cross sections of the thin films were prepared with the lift-out technique using a dual-beam focused ion beam (FIB-SEM 1540 ESB, Zeiss, Germany) with a Ga ion source. ${ }^{28} \mathrm{~A}$ Pt layer was deposited prior to the milling in order to protect the $\mathrm{CN}_{\mathrm{x}}$ films from the Ga beam. The cross sections were prepared using an ion energy of $30 \mathrm{kV}$. Currents of $2 \mathrm{nA}, 1 \mathrm{nA}, 500 \mathrm{pA}, 200 \mathrm{pA}, 100 \mathrm{pA}$, and $20 \mathrm{pA}$ were sequentially used for the preparation of the TEM lamella. For the final polishing of the lamella, a Ga ion energy of $5 \mathrm{kV}$ at $100 \mathrm{pA}$ was applied to minimize surface amorphization of the $\mathrm{CN}_{\mathrm{x}}$ films and to decrease the probability of Ga implantation.

In order to investigate the $\mathrm{CN}_{\mathrm{x}}$ film compositions and assign the bonding states, X-ray photoelectron spectroscopy (XPS) was carried out using an Axis Ultra DLD (Kratos Analytical, UK) instrument equipped with a monochromatic $\mathrm{Al} \mathrm{K}$ source $(\mathrm{h} \nu=1486.69 \mathrm{eV})$ operating at a base pressure of $1.5 \times 10^{-7} \mathrm{~Pa}$. C1s, N1s, O1s, and Ar2p core level spectra were acquired, on as-deposited samples and after $300 \mathrm{~s}$ of sputter cleaning using a $500 \mathrm{eV} \mathrm{Ar}^{+}$ion beam with an incident angle of $70^{\circ}$ from the surface normal. A Shirley type background and Voigt peak shape, with the Lorentzian contribution restricted to $20 \%$ were used to create peak fit models for the evaluation of the $\mathrm{CN}_{\mathrm{x}}$ bonding states. Here, the $\mathrm{C} 1 \mathrm{~s}$ and N1s core level spectra obtained from as-deposited samples were considered. The full-width-at-half-maximum (FWHM) of contributions in the peak fit models was constraint to $2 \mathrm{eV}$. The quantification of the $\mathrm{CN}_{\mathrm{x}}$ film composition, based on the $\mathrm{C} 1 \mathrm{~s}, \mathrm{~N} 1 \mathrm{~s}$, and $\mathrm{O} 1 \mathrm{~s}$ core level spectra, was performed on sputter-cleaned samples using CASAXPS software (version 2.3.16) together with sensitivity factors supplied by Kratos Analytical, Ltd.

Micro-Raman spectroscopy was performed using a $532 \mathrm{~nm}$ single-mode laser for excitation and a high-resolution single monochromator (Jobin-Yvon, model HR460) equipped with a CCD camera. The resolution of the system equipped with a $600 \mathrm{~g} / \mathrm{mm}$ grating was $\sim 2 \mathrm{~cm}^{-1}$. The laser power was kept at $\sim 0.5 \mathrm{~mW}$ in order to avoid thermal damage of the samples. The laser spot on the sample was $\sim 1 \mu \mathrm{m}$ in diameter using an objective with numerical aperture 0.95 and magnification 100. The acquisition time for all presented spectra was $30 \mathrm{~s}$. A Gaussian function was used for the deconvolution of the D and G bands in order to extract the FWHM and I(D)/ $\mathrm{I}(\mathrm{G})$ peak area ratio.

Elemental depth profiles of the deposited films were obtained by time-of-flight ERDA (ToF-ERDA). The measurements were performed with a $36 \mathrm{MeV}^{127} \mathrm{I}^{8+}$ primary ion beam incident at $67.5^{\circ}$ relative to the surface normal and a recoil angle of $45^{\circ} \cdot{ }^{29,30}$ All recoil ToF-ERDA spectra were analyzed using the CONTES code, ${ }^{31}$ where the measured recoil energy spectrum of each element was converted to relative atomic concentration profiles.

Cross-sectional scanning electron microscopy (SEM, LEO 1550 Gemini, Zeiss, Germany) was used to determine the thickness and study the morphology of the $\mathrm{CN}_{\mathrm{x}}$ films.

X-ray reflectivity (XRR) was performed to determine the density of the films using an Empyrean MRD x-ray diffractometer (PANalytical, Holland), equipped with a $\mathrm{Cu} \mathrm{K}_{\mathrm{a}}$ radiation (1.54 $\AA$ ) source, a hybrid Ge(220) monochromator, and a parallel plate collimator at the 3D PIXcel detector. X'PERT reflectivity software and a generic algorithm were chosen for the fitting of the reflectivity spectra. Three layers were used for the fitting model, representing the Si substrate with a thickness of $525 \mu \mathrm{m}$, the native silicone oxide layer (with $2 \mathrm{~nm}$ thickness) at the (Si substrate) $/\left(\mathrm{CN}_{\mathrm{x}}\right.$ film $)$ interface and a $\mathrm{CN}_{\mathrm{x}}$ layer of $1 \mu \mathrm{m}$ thickness.

In order to assess the residual film stresses, measurements on samples with a size of $3 \times 2 \mathrm{~cm}$ were performed with a Dektak 6M stylus surface profilometer (Veeco, USA). Data were acquired electromechanically with a diamond stylus coupled to a Linear Variable Differential Transformer. The radius of curvature was extracted and the modified Stoney's formula, Eq. (1), for thin films was used to calculate the residual film stress, $\sigma_{\mathrm{CN}_{x}}$,

$$
\sigma_{\mathrm{CN}_{\mathrm{x}}}=Y_{\mathrm{Si}} d_{\mathrm{Si}}^{2} / 6 \mathrm{R}\left(1-v_{\mathrm{Si}}\right) d_{\mathrm{CN}_{\mathrm{x}}},
$$

where $d_{\mathrm{Si}}, \nu_{\mathrm{Si}}$, and $Y_{\mathrm{Si}}$ are the thickness, the Poisson's ratio, and the Young's modulus of the Si substrate, respectively $\left[d_{\mathrm{Si}}=525 \mu \mathrm{m}, \nu_{\mathrm{Si}}=0.36\right.$, and $Y_{\mathrm{Si}}=169 \mathrm{GPa}$ (Ref. 32)], $d_{\mathrm{CN}_{\mathrm{x}}}$ is the thickness of the $\mathrm{CN}_{\mathrm{x}}$ film as measured by SEM cross sections, and $R$ is the radius of curvature of each individual sample. ${ }^{33} R$ was corrected with the radius of curvature obtained from an uncoated Si substrate.

The mechanical properties of the $\mathrm{CN}_{\mathrm{x}}$ films were investigated by nanoindentation using a Triboindenter TI 950 (Hysitron, USA) and a Berkovich tip with an apex radius of $\sim 100 \mathrm{~nm}$. The mechanical response of the $\mathrm{CN}_{\mathrm{x}}$ thin films 
was recorded for 20 nanoindents per sample and evaluated based on the approach by Oliver and Pharr. ${ }^{34}$ The maximum load was constrained to $1500 \mu \mathrm{N}$, corresponding to a penetration depth ranging between 100 and $45 \mathrm{~nm}$. The elastic recovery (ER) of the films was calculated using following equation:

$$
\frac{\left(L_{\max }-L_{\mathrm{res}}\right)}{L_{\max }} 100 \%
$$

where $L_{\max }$ is the indentation depth at maximum load, and $L_{\text {res }}$ is the residual depth after unloading. The tribological response of the $\mathrm{CN}_{\mathrm{x}}$ films was studied with reciprocal wear tests in air using a Triboindenter TI 950 (Hysitron, USA), equipped with a conical tip with an apex radius of $\sim 5 \mu \mathrm{m}$. A load of $5 \mathrm{mN}$, resulting in a contact pressure of $\sim 8.5 \mathrm{GPa}$, was used for the measurements. The track length was set to $5 \mu \mathrm{m}$. Each test comprised 31 cycles, where one cycle is considered to be one sweep forward and one backward. The coefficient of friction, $\mu$, and the profile of the worn film surface were recorded consecutively. After the first 6 cycles, the average steady-state coefficient of friction was extracted and wear was calculated after 31 cycles. During the wear tests, the ambient temperature was held at $\sim 22^{\circ} \mathrm{C}$ and the relative humidity was $\sim 30 \%-40 \%$.

\section{RESULTS AND DISCUSSION}

\section{A. Thin film structure, composition, and bonding}

Figure 2 shows cross-sectional SEM images of the $\mathrm{CN}_{\mathrm{x}}$ thin films deposited at $\mathrm{V}_{\mathrm{s}}=20,60$, and $120 \mathrm{~V}$ under MFMS [Figs. 2(a)-2(c)], HiPIMS [Figs. 2(d)-2(f)], and DCMS [Figs. $2(\mathrm{~g})-2(\mathrm{i})]$ conditions. The films deposited at $\mathrm{V}_{\mathrm{s}}=100 \mathrm{~V}$ are omitted, since the morphology of the films grown in HiPIMS and DCMS modes at $100 \mathrm{~V}$ is similar to those grown at $60 \mathrm{~V}$ in the corresponding sputter mode, while the morphology of the film deposited by MFMS at $\mathrm{V}_{\mathrm{s}}=100 \mathrm{~V}$ resembles by the morphology of the film deposited at $\mathrm{V}_{\mathrm{s}}=120 \mathrm{~V}$.

At $\mathrm{V}_{\mathrm{s}}=20 \mathrm{~V}$, all three deposition techniques produced films with apparent columns. MFMS [Figs. 2(a)-2(c)] effectively decreases the porosity of the films at $\mathrm{V}_{\mathrm{s}} \geq 60 \mathrm{~V}$, while HiPIMS [Figs. 2(d)-2(f)] produces columnar structured films. Only at $\mathrm{V}_{\mathrm{s}}=120 \mathrm{~V}$, the columnar structure is significantly attenuated in HiPIMS mode. Films produced by DCMS [Figs. 2(g)-2(i)] show a decreased porosity at $\mathrm{V}_{\mathrm{s}} \geq 100 \mathrm{~V}$. The differences in film morphology comparing the different deposition techniques are caused by the different ion irradiation conditions that are specific for each method. Not only the ion density is expected to vary, but also the bias duty cycle is different for each of the techniques tested. In the case of films deposited by HiPIMS, the bias pulse length of $200 \mu \mathrm{s}$ effectively limits the influence of low-energy $\mathrm{Ar}^{+}$ion irradiation that arrives at the growing film surface at $\mathrm{t}>200 \mu$ s, i.e., when the substrate is at the floating potential. ${ }^{35}$ This is in contrast to films grown by the two other techniques (MFMS or DCMS), in which case the substrate bias duty cycle is significantly higher, $44 \%$ and $100 \%$, respectively, resulting in more severe $\mathrm{Ar}^{+}$ion bombardment, leading to an increased extent of forward sputtering, and thus higher densification for a given $\mathrm{V}_{\mathrm{s}}$ (ion energy) as compared to HiPIMS.

In addition, MFMS plasmas are expected to contain higher amounts of ions due to their special cathode-anode configuration, where cathodes operate against each other, confining the ions in the working region and allowing densification at lower $\mathrm{V}_{\mathrm{s}}$. Moreover, a considerable amount of $\mathrm{Ar}^{2+}$ ions (that was $\sim 7$ times higher than in HiPIMS processes and $\sim 100$ times higher than in DCMS processes) was observed in a similar experimental MFMS process set up using a $\mathrm{Si} / \mathrm{Ar} /$ $16 \% \mathrm{~N}_{2}$ discharge. As $\mathrm{V}_{\mathrm{s}}$ increases, the energy of the incident ions rises. This induces forward sputtering and renucleation at the film surface resulting in a densified morphology, where the films appear increasingly homogeneous and the columnar morphology is replaced by fine, more equiaxed grains.

Low substrate temperatures $\left(\leq 300^{\circ} \mathrm{C}\right)$ in physical vapor deposition tend to yield low density $\mathrm{C}$ films. ${ }^{36}$ The density of our films, $\rho_{\mathrm{c}}$, corrected for the presence of $\mathrm{Ar}$, is plotted in Fig. 3(a) as a function of $\mathrm{V}_{\mathrm{s}}$. Index c indicates the corrected values of density, $\rho$. The values of $\rho_{\mathrm{c}}$ of $\mathrm{CN}_{\mathrm{x}}$ films deposited with each technique are also collected in Table I. For all three techniques, $\rho_{\mathrm{c}}$ increases with increasing $\mathrm{V}_{\mathrm{s}}$. At a low $\mathrm{V}_{\mathrm{s}}$ of $20 \mathrm{~V}$, all films showed a $\rho_{\mathrm{c}} \leq 1.85 \pm 0.02 \mathrm{~g} / \mathrm{cm}^{3}$, which is less than the density of sputtered $\mathrm{C}$ and $\mathrm{CN}_{\mathrm{x}}(2.2 \mathrm{~g} /$ $\left.\mathrm{cm}^{3}\right),{ }^{9,37}$ and in agreement with the SEM images in Fig. 2, which show open columnar structures. At $\mathrm{V}_{\mathrm{s}}=120 \mathrm{~V}$, the density increases to $\sim 2.3 \pm 0.03 \mathrm{~g} / \mathrm{cm}^{3}$ for HiPIMS and MFMS and is thus comparable to that of graphite. As elaborated above, densification is a result of increased ion energy as $\mathrm{V}_{\mathrm{s}}$ increases and is consistent with a porous-free, columnless morphology observed by SEM.

The $\mathrm{O}$ content of the films as presented in Fig. 3(b) was obtained from XPS measurements after $\mathrm{Ar}^{+}$sputter cleaning. Comparable contents were also obtained from ERDA measurements. The $\mathrm{O}$ uptake results primarily from exposure of the films to atmosphere subsequent to the depositions. Thus, the film porosity determines the measured $\mathrm{O}$ content to a high extent. Generally, the O content decreases with increasing $\mathrm{V}_{\mathrm{s}}$, corroborating an increasing film density, which is consistent with above presented SEM and XRR results. The highest $\mathrm{O}$ concentrations are obtained from films deposited at $\mathrm{V}_{\mathrm{s}}=20 \mathrm{~V}$, with values ranging between 1.2 and 1.5 at. \%. The lowest values of $0.2 \pm 0.1$ at. $\%$ are observed for films deposited by MFMS and DCMS using a $\mathrm{V}_{\mathrm{s}}$ of $120 \mathrm{~V}$, while the $\mathrm{O}$ content of $\mathrm{CN}_{\mathrm{x}}$ films deposited by HiPIMS at $\mathrm{V}_{\mathrm{s}}=120 \mathrm{~V}(0.3 \pm 0.1$ at. $\%)$ was slightly, but not significantly higher. In the case of $\mathrm{CN}_{\mathrm{x}}$ films grown by HiPIMS, the $\mathrm{O}$ content is comparatively high, even for $\mathrm{V}_{\mathrm{s}}=100 \mathrm{~V}$, indicating an elevated degree of porosity. This was also observed in corresponding SEM cross sections [Figs. 2(d) and 2(e)]. Eventually, the intercolumnar voids close at $\mathrm{V}_{\mathrm{s}}=120 \mathrm{~V}$ and the $\mathrm{O}$ content decreases to very low levels [Fig. 3(b)]. For films deposited by MFMS and DCMS, this is observed at $\mathrm{V}_{\mathrm{s}}=60 \mathrm{~V}$ and $\mathrm{V}_{\mathrm{s}}=100 \mathrm{~V}$, respectively.

In Fig. 3(c), the Ar content in the $\mathrm{CN}_{\mathrm{x}}$ films as obtained by ERDA measurements is plotted as a function of $\mathrm{V}_{\mathrm{s}}$ for the three deposition methods. For all investigated $\mathrm{V}_{\mathrm{s}}$, the $\mathrm{Ar}$ content is lowest in films grown by HiPIMS. Here, the $\mathrm{Ar}$ 


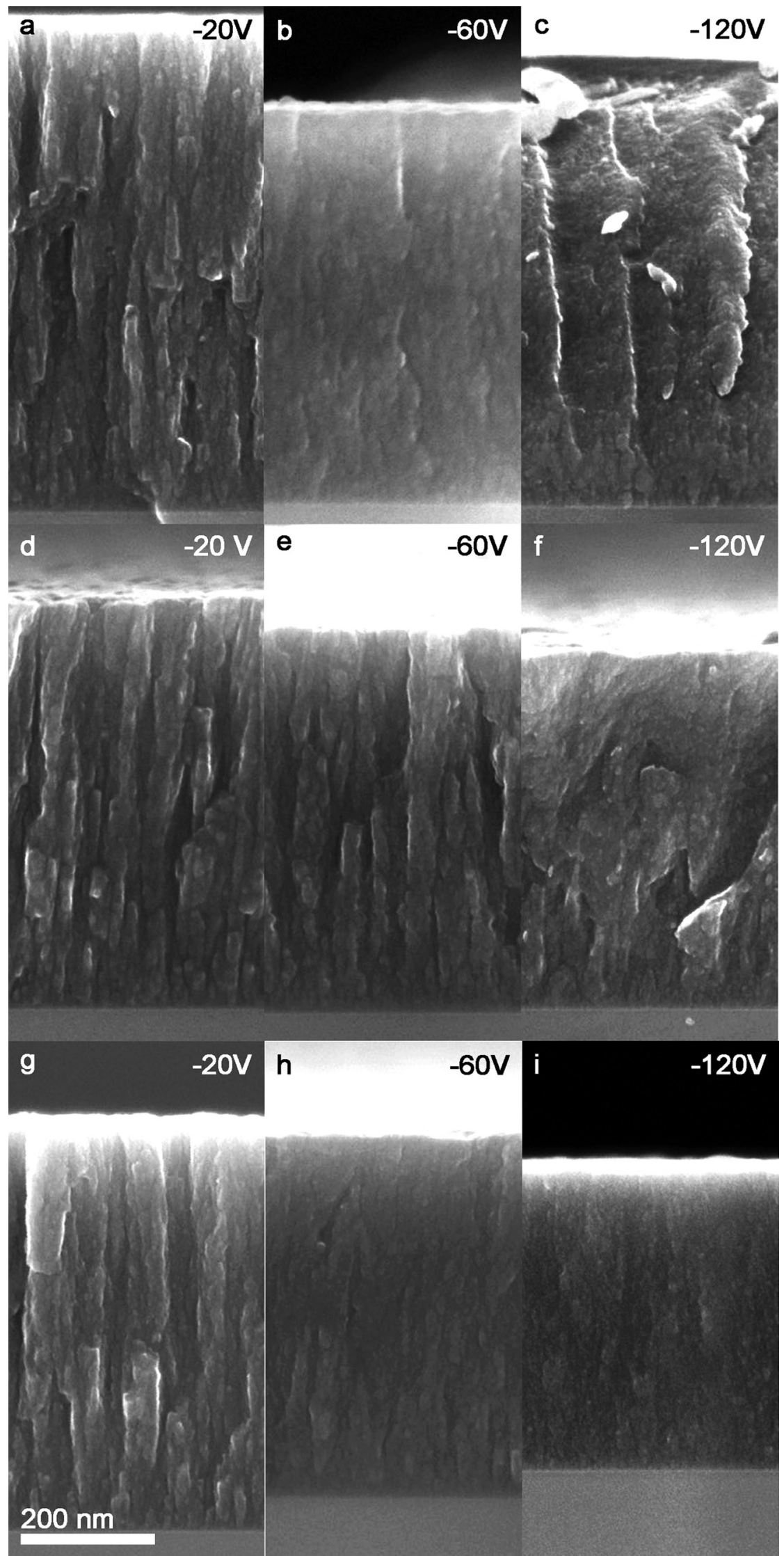

FIG. 2. SEM cross sections from the $\mathrm{CN}_{\mathrm{x}}$ films deposited under (a)-(c) MFMS, (d)-(f) HiPIMS, and (g)-(i) DCMS conditions at different $\mathrm{V}_{\mathrm{s}}$. 


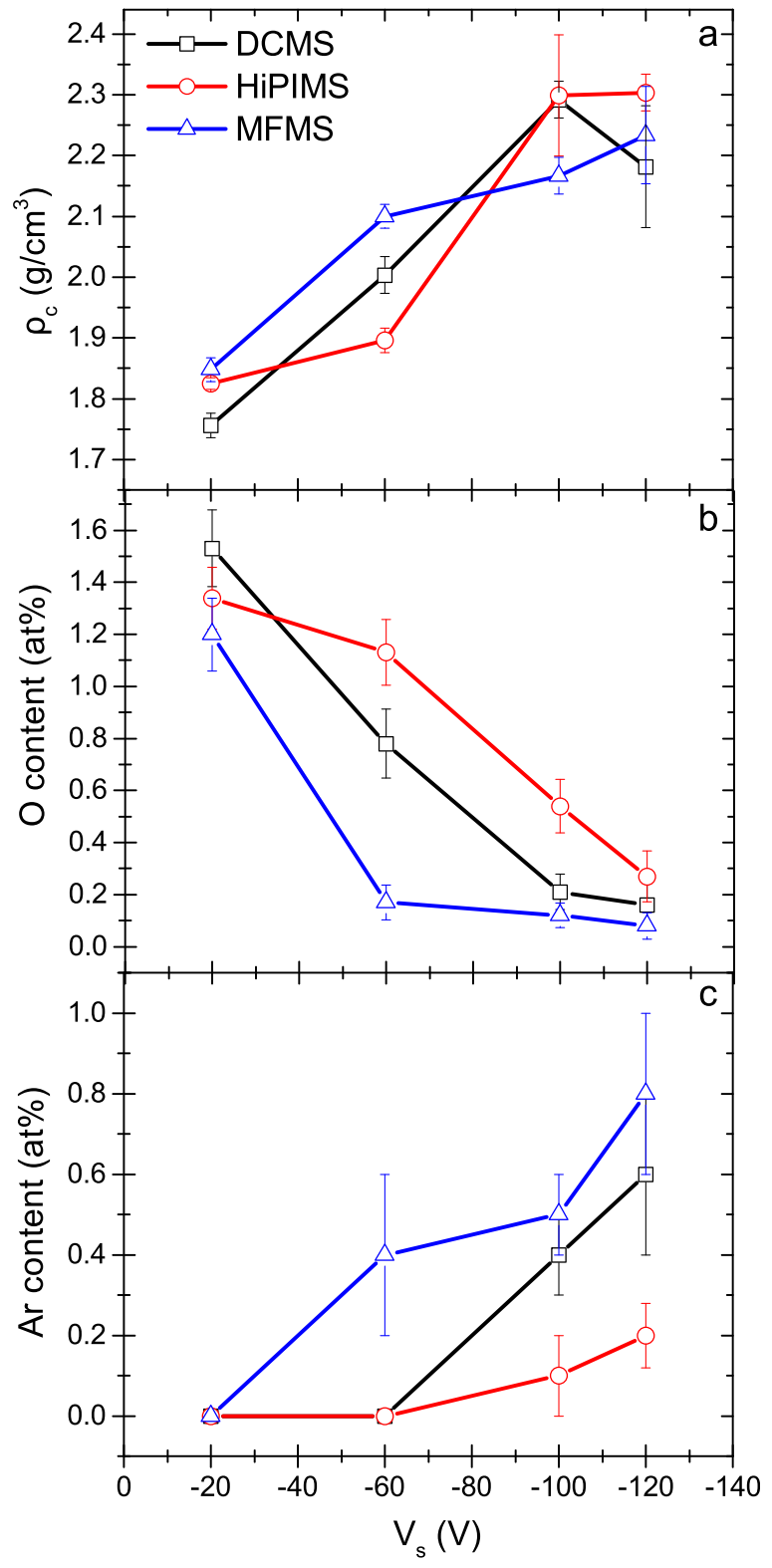

FIG. 3. (Color online) (a) Density, (b) O content, and (c) Ar content of the $\mathrm{CN}_{\mathrm{x}}$ films deposited by MFMS, HiPIMS, and DCMS as a function of $\mathrm{V}_{\mathrm{s}}$. O contents were obtained from XPS measurements after sputter cleaning with $\mathrm{Ar}^{+}$ions. Ar contents were obtained from ERDA measurements.

content does not exceed 0.2 at. \%. The highest amount of $\mathrm{Ar}$ $(0.8 \pm 0.2$ at. \%) was found in films grown by MFMS at $\mathrm{V}_{\mathrm{s}}=120 \mathrm{~V}$. The different Ar uptake for each technique is ascribed to a combination of the significantly different bias duty cycles and the different Ar ion densities. As described above, lower bias duty cycles and lower amounts of single and double charged Ar ions in the plasma yield less Ar ion irradiation of the growing film and thus, reduced Ar incorporation. Furthermore, mass spectrometry studies have shown a significant difference between HiPIMS and DCMS plasmas, regarding the amount of specific ion species. The amount of $\mathrm{Ar}^{+}, \mathrm{N}^{+}$, and $\mathrm{N}^{2+}$ ions is similar in HiPIMS and DCMS plasmas, though HiPIMS plasmas contain additionally more molecular $\mathrm{CN}^{+}$and $\mathrm{C}_{2} \mathrm{~N}^{+}$as well as $\mathrm{C}^{+}$species. ${ }^{9}$ Due to the continuous biasing in DCMS processes, a comparatively high
TABLE I. Hardness $(\mathrm{H})$, reduced elastic modulus $\left(\mathrm{E}_{\mathrm{r}}\right)$, elastic recovery (ER), and density $\rho_{\mathrm{c}}$ of $\mathrm{CN}_{\mathrm{x}}$ deposited in MFMS, HiPIMS, and DCMS mode.

\begin{tabular}{lrrrrl}
\hline \hline Methods & $\mathrm{V}_{\mathrm{s}}(\mathrm{V})$ & $\mathrm{H}(\mathrm{GPa})$ & $\mathrm{E}_{\mathrm{r}}(\mathrm{GPa})$ & $\mathrm{ER}(\%)$ & $\rho_{\mathrm{c}}\left(\mathrm{g} / \mathrm{cm}^{3}\right)$ \\
\hline MFMS & 20 & 8.2 & 76.3 & 78.2 & 1.85 \\
MFMS & 60 & 14.7 & 142.8 & 77.7 & 2.1 \\
MFMS & 100 & 20.9 & 156.9 & 87.8 & 2.17 \\
MFMS & 120 & 24.6 & 191.9 & 90.7 & 2.23 \\
HiPIMS & 20 & 7.8 & 76.2 & 76 & 1.83 \\
HiPIMS & 60 & 8.9 & 90.9 & 73.5 & 1.9 \\
HiPIMS & 100 & 11.8 & 116.7 & 72.1 & 2.3 \\
HiPIMS & 120 & 13.3 & 137.9 & 74.4 & 2.3 \\
DCMS & 20 & 7.3 & 71.5 & 77.2 & 1.76 \\
DCMS & 60 & 11.1 & 180.6 & 73.8 & 2 \\
DCMS & 100 & 15.2 & 119.6 & 82.8 & 2.29 \\
DCMS & 120 & 18.4 & 172.2 & 83.4 & 2.18 \\
\hline \hline
\end{tabular}

amount of ions is attracted and impinges on the substrates, resulting in a higher Ar incorporation. In HiPIMS processes, on the other hand, ions are only attracted during the short bias pulses, resulting in lower $\mathrm{Ar}$ contents in the $\mathrm{CN}_{\mathrm{x}}$ coatings. Figure 4(a) shows the $N / C$ ratio as a function of $\mathrm{V}_{\mathrm{s}}$, as obtained from XPS analysis subsequently to $\mathrm{Ar}^{+}$sputter cleaning. The $N / C$ ratio of the $\mathrm{CN}_{\mathrm{x}}$ films deposited by MFMS decreases linearly with increasing $\mathrm{V}_{\mathrm{s}}$. For films deposited by DCMS and HiPIMS, the $N / C$ ratio shows a maximum at $\mathrm{V}_{\mathrm{s}}=60 \mathrm{~V}$. The $\mathrm{N}$ content of films deposited by MFMS and DCMS is higher than in case HiPIMS is used.

The lower $N / C$ ratio extracted for films deposited at higher $\mathrm{V}_{\mathrm{s}}$ can be attributed to higher resputtering rates of $\mathrm{N}$-containing species from the film surface. ${ }^{19,38}$ This is confirmed by the density and the deposited mass per area and time, $\mathrm{m}_{\mathrm{d}}$, of the $\mathrm{CN}_{\mathrm{x}}$ films, as demonstrated in Figs. 3(a) and 4(b), respectively. The $m_{d}$ was determined from the deposition rate and density of the $\mathrm{CN}_{\mathrm{x}}$ films, using SEM cross sections and XRR measurements, respectively. For all investigated films, $\mathrm{m}_{\mathrm{d}}$ shows a decreasing trend with increasing $\mathrm{V}_{\mathrm{s}}$ and is not significantly affected by the deposition mode. For films deposited by MFMS up to $\mathrm{V}_{\mathrm{s}}=100 \mathrm{~V}$, the decreased $\mathrm{m}_{\mathrm{d}}$ in combination with the decreased $N / C$ ratios indicates that progressively $\mathrm{N}$-rich species are resputtered from the growing $\mathrm{CN}_{\mathrm{x}}$ film surface. An increase of $\mathrm{m}_{\mathrm{d}}$ at $120 \mathrm{~V}$ implies that resputtering slightly decreases, whereas even more $\mathrm{N}$ is removed from the film surface. For films grown by HiPIMS, the rather constant $\mathrm{m}_{\mathrm{d}}$ and $N / C$ ratios indicate a process without or less resputtering. For films deposited by DCMS, $m_{d}$ decreases linearly with increasing $\mathrm{V}_{\mathrm{s}}$. This indicates that resputtering also takes place in DCMS mode. However, the corresponding $N / C$ ratios suggest that the resputtering rate of $\mathrm{N}$-rich species picks up as $\mathrm{V}_{\mathrm{s}}$ approaches 100 and $120 \mathrm{~V}$, where reduced $\mathrm{N}$ concentrations are observed.

XPS was used to determine $\mathrm{C}$ and $\mathrm{N}$ bonding configurations for all $\mathrm{CN}_{\mathrm{x}}$ films. Figures 5(a)-5(c) show the normalized C1s core level spectra and Figs. 5(d)-5(f) the corresponding normalized N1s core level spectra for films deposited by the three deposition techniques and the chosen $\mathrm{V}_{\mathrm{s}}$. The presented core level spectra were obtained from asdeposited samples in order to show unaffected (i.e., from 


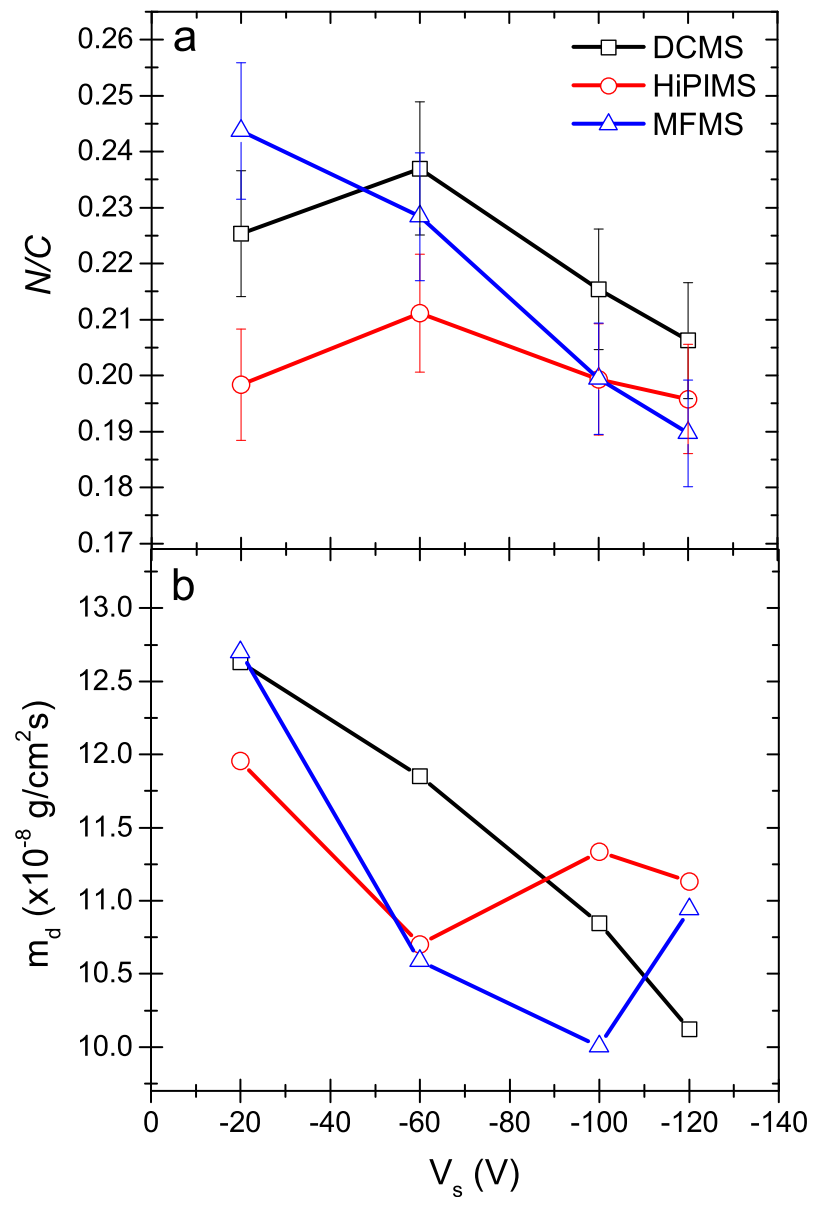

FIG. 4. (Color online) (a) N/C ratio and (b) deposited mass per area and time $\left(\mathrm{m}_{\mathrm{d}}\right)$ of $\mathrm{CN}_{\mathrm{x}}$ films deposited by MFMS, HiPIMS, and DCMS as a function of $\mathrm{V}_{\mathrm{s}}$. The $N / C$ ratio was extracted by XPS measurements after $300 \mathrm{~s}$ sputter cleaning. The deposited mass per area and time was extracted by the film thickness and density from SEM cross sections and XRR measurements, respectively.

sputter-cleaning) $\mathrm{C}$ and $\mathrm{N}$ bonding configurations in the films. The $\mathrm{C} 1 \mathrm{~s}$ core level spectra can be satisfactorily fitted with five components; $C l$ assigned to $s p^{2}$ hybridized $\mathrm{C}-\mathrm{C}$ bonds $(\sim 284.8 \pm 0.2 \mathrm{eV}), C 2$ assigned to $s p^{3}$-hybridized $\mathrm{C}$ bonds $(\sim 286 \pm 0.2 \mathrm{eV}), C 3$ resembling $s p^{2}$ or $s p^{3}$-hybridized $\mathrm{C}-\mathrm{N}$ bonds $(\sim 287.6 \pm 0.2 \mathrm{eV})$, as well as $C 4$ $(289.1 \pm 0.2 \mathrm{eV})$ and $C 5(290 \pm 0.2 \mathrm{eV})$ resembling $\mathrm{C}-\mathrm{O}$ and $\mathrm{C}=\mathrm{O}$ bonds, respectively. ${ }^{39,40}$ For all films, the $\mathrm{C} 1 \mathrm{~s}$ core level spectra are broadened as $\mathrm{V}_{\mathrm{s}}$ increases, suggesting elevated amounts of $s p^{2}$-hybridized $\mathrm{C}$. The width of the $\mathrm{C} 1 \mathrm{~s}$ core level spectra scales not only with $\mathrm{V}_{\mathrm{s}}$ but also with the $\mathrm{Ar}$ content in the films. Considering the highest $\mathrm{V}_{\mathrm{s}}$, the broadening of the $\mathrm{C} 1 \mathrm{~s}$ spectra is most pronounced for $\mathrm{CN}_{\mathrm{x}}$ films deposited in MFMS mode. The broadening of the $\mathrm{C} 1 \mathrm{~s}$ core level region decreases for films deposited by DCMS and is least distinct as HiPIMS is used. As considered above, this is a consequence of the significantly different bias duty cycles together with the inert gas ion densities of the deposition modes. $\mathrm{C}-\mathrm{N}$ bonds introduce both $s p^{3}$ and $s p^{2}$-hybridized bonding configurations and are expected to contribute to $C 2$ and $C 3$. Therefore, the broadening of the $\mathrm{C} 1 \mathrm{~s}$ core level spectra cannot be exclusively assigned to
$\mathrm{C}-\mathrm{C}$ or $\mathrm{C}-\mathrm{N}$ bonds in $s p^{2}$ or $s p^{3}$-configuration, since these peaks constitute an intermixing of $s p^{2}$ and $s p^{3} \mathrm{C}-\mathrm{C}$ and/or $\mathrm{C}-\mathrm{N}$ bonds. The $\mathrm{C}-\mathrm{C} s p^{2}$ content, extracted only from $\mathrm{Cl}$ of the films deposited by MFMS and DCMS, increases with increasing $\mathrm{V}_{\mathrm{s}}$, while the $\mathrm{C} 1 \mathrm{~s}$ component for films deposited in HiPIMS mode hardly changes. For films deposited by MFMS, an increase of $s p^{2}$-hybridized C from 26.6 at. \% at $\mathrm{V}_{\mathrm{s}}=20 \mathrm{~V}$ to 34.5 at. $\%$ at $\mathrm{V}_{\mathrm{s}}=120 \mathrm{~V}$ was extracted from $C 1$. The $\mathrm{C} s p^{2}$ content of films deposited by HiPIMS shows the lowest variation with values of 28.8 at. $\%$ at $\mathrm{V}_{\mathrm{s}}=20 \mathrm{~V}$ to 33.2 at. $\%$ at $\mathrm{V}_{\mathrm{s}}=120 \mathrm{~V}$. Films grown by DCMS present $s p^{2}$ contents ranging between 27.5 at. $\%$ for $\mathrm{V}_{\mathrm{s}}=20 \mathrm{~V}$ and 33.2 at. $\%$ for $\mathrm{V}_{\mathrm{s}}=120 \mathrm{~V}$. Consequently, the $s p^{2} / s p^{3}$ ratio, extracted only from $C 1$ and $C 2$ components, appears to increase distinctly with increasing $\mathrm{V}_{\mathrm{s}}$ in the case MFMS and DCMS processes are used for the deposition of $\mathrm{CN}_{\mathrm{x}}$, while the $s p^{2} / s p^{3}$ ratio in films grown by HiPIMS presents only small changes. The N1s core level spectra can be satisfactorily fitted with three components; N1 $(\sim 398.6 \pm 0.2 \mathrm{eV})$ attributed to $\mathrm{N}$ bond in two-fold coordination at the periphery of graphene sheets in a $\mathrm{C}$ matrix (pyridine-like structure), $N 2(\sim 400.6 \pm 0.1 \mathrm{eV})$ is commonly attributed to $s p^{2}$-hybridized $\mathrm{N}$ bond to three $\mathrm{C}$ atoms in a graphitic network, and $N 3(\sim 402.7 \pm 0.1 \mathrm{eV})$ arises due to N-O bonds. ${ }^{12,16,41}$

The positions of $N 1$ and $N 2$ peaks as well as the N2/N1 peak area ratio indicate the degree of SRO of the $\mathrm{C}$ network. Fullerene-like microstructures are usually observed for $\mathrm{N} 2 /$ $N 1$ ratios higher than one and for a $N 1-N 2$ peak separation of $\sim 2 \mathrm{eV} .^{12,42}$ The here investigated films show a $N 2 / N 1$ ratio $<1$ and the separation of the peaks is lower than $2 \mathrm{eV}$, indicating that all films have an amorphous microstructure without apparent SRO. ${ }^{12}$ This is in agreement with results from HRTEM imaging and SAED, as shown in Fig. 6. The TEM micrograph together with the corresponding SAED pattern is representative for all investigated films. Both indicate an amorphous film microstructure with scattering distances at $\sim 2.1 \AA$ and $\sim 1.1 \AA$, being typical for amorphous $\mathrm{CN}_{\mathrm{x}}$ films. ${ }^{9}$ The $\sim 2 \mathrm{~nm}$ interfacial layer between the $\mathrm{CN}_{\mathrm{x}}$ film and the $\mathrm{Si}$ substrate is ascribed to the formation of $\mathrm{SiO}_{2}$ at the surface of the substrates, due to the exposure to atmosphere prior to depositions.

Raman spectra recorded for all $\mathrm{CN}_{\mathrm{x}}$ films are shown in Figs. 7(a)-7(c). The spectra exhibit one dominant and one weaker band (denoted $\mathrm{CN}$ ). The most prominent band is dominated by two contributions at $\sim 1380$ and $\sim 1560 \mathrm{~cm}^{-1}$ corresponding to the disordered (D) and graphitic (G) mode, respectively. The individual positions and linewidths of the $\mathrm{D}$ and $\mathrm{G}$ contributions have been obtained by fitting the band using Gaussian peak shapes for both D and G. The D and G bands are observed at similar positions as in pure carbon films, and both have been associated with $s p^{2} \mathrm{C}$ sites. ${ }^{15}$ The small peak at $\sim 2200 \mathrm{~cm}^{-1}$ has been assigned previously to contributions from $s p^{l} \mathrm{C} \equiv \mathrm{N}$ modes. ${ }^{15}$ According to Ferrari et al. ${ }^{15}$ the $\mathrm{G}$ band arises due to the $\mathrm{C}-\mathrm{C}$ stretching vibrations of $s p^{2}$ bonds, while the $\mathrm{D}$ band is due to the bond breathing modes in both $s p^{2}$ rings and chains. For all deposition techniques, the $\mathrm{D}$ and $\mathrm{G}$ bands are better resolved for 


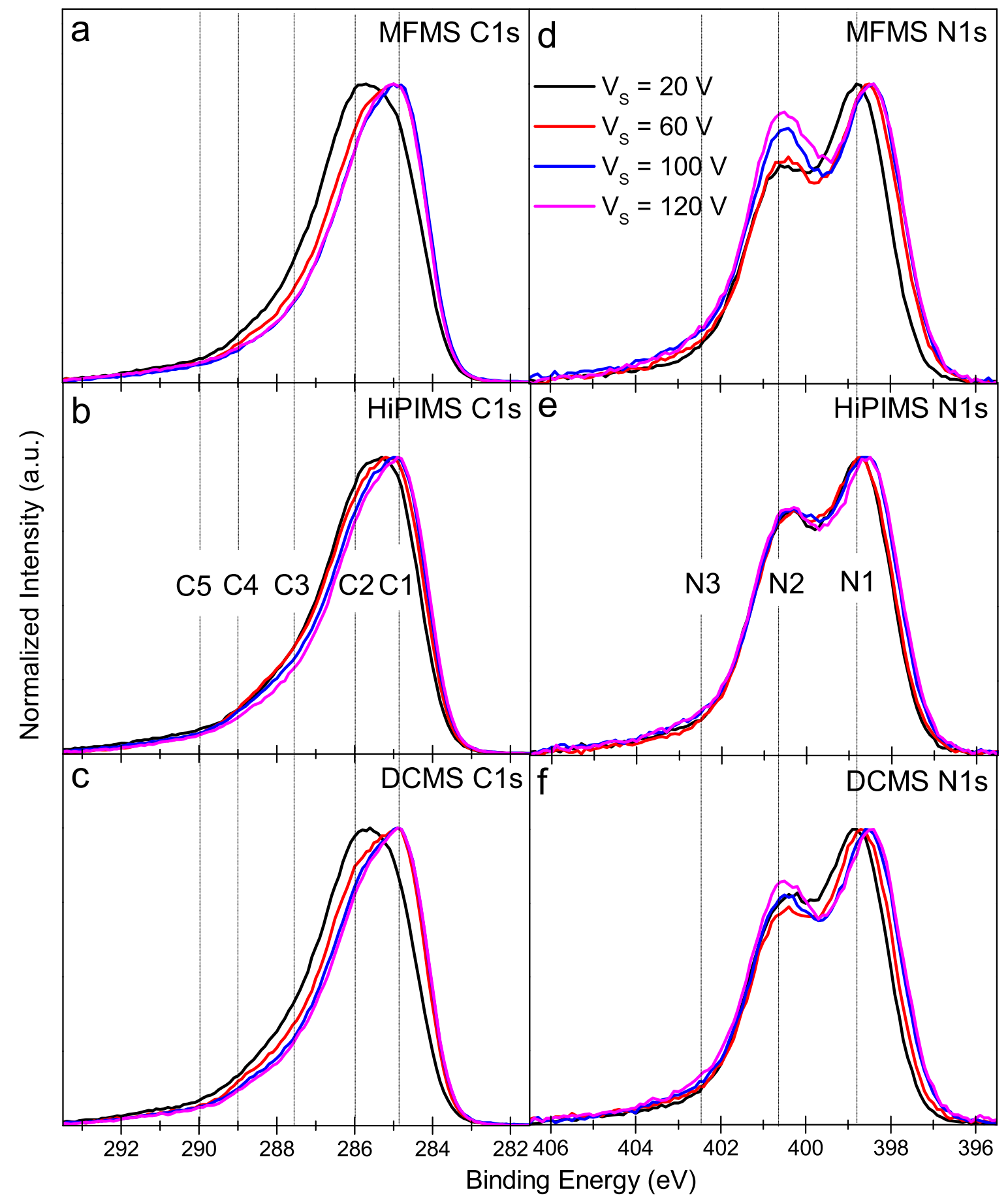

FIG. 5. (Color online) (a)-(c) Normalized C1s core level spectra for films deposited with (a) MFMS, (b) HiPIMS, and (c) DCMS and (d)-(f) normalized N1s core level spectra for films produced by (d) MFMS, (e) HiPIMS, and (f) DCMS. Films deposited at $\mathrm{V}_{\mathrm{s}}=20,60,100$, and $120 \mathrm{~V}$ are presented. All core level spectra were acquired from as-deposited samples.

$\mathrm{CN}_{\mathrm{x}}$ films deposited at $\mathrm{V}_{\mathrm{s}}=20 \mathrm{~V}$ (cf. black curves in Fig. 7) than for the films deposited at higher $\mathrm{V}_{\mathrm{s}}$. For $\mathrm{CN}_{\mathrm{x}}$ films grown at higher $V_{s}$, this distinction is less apparent as the $G$ band shifts toward lower wavenumbers and the D band becomes broader. The shift of the $\mathrm{G}$ bands is not significant enough to justify conclusions with regards to changes in the $\mathrm{C}-\mathrm{C}$ stretching modes. However, the broadening of the D band with increasing $\mathrm{V}_{\mathrm{s}}$ is well pronounced for each technique and implies changes in the breathing modes of the $\mathrm{C}$ $s p^{2}$ sites in rings. This correlates well with the results by XPS from the deconvolution of the C1s core level spectra; here, an increased amount of $s p^{2}$-hybridized $\mathrm{C}$ was extracted from the $C l$ components with increasing $\mathrm{V}_{\mathrm{s}}$. The $\mathrm{I}(\mathrm{D}) / \mathrm{I}(\mathrm{G})$ ratio is associated with the number of graphitic $\left(s p^{2}\right)$ domains or the degree of $s p^{2}$ clustering in pure carbon films, ${ }^{43}$ where $\mathrm{I}(\mathrm{D})$ and $\mathrm{I}(\mathrm{G})$ are the peak intensities of the $\mathrm{D}$ and $\mathrm{G}$ bands, respectively. In all cases, the deconvolution of the compound band by Gaussian peak shapes shows a broad 


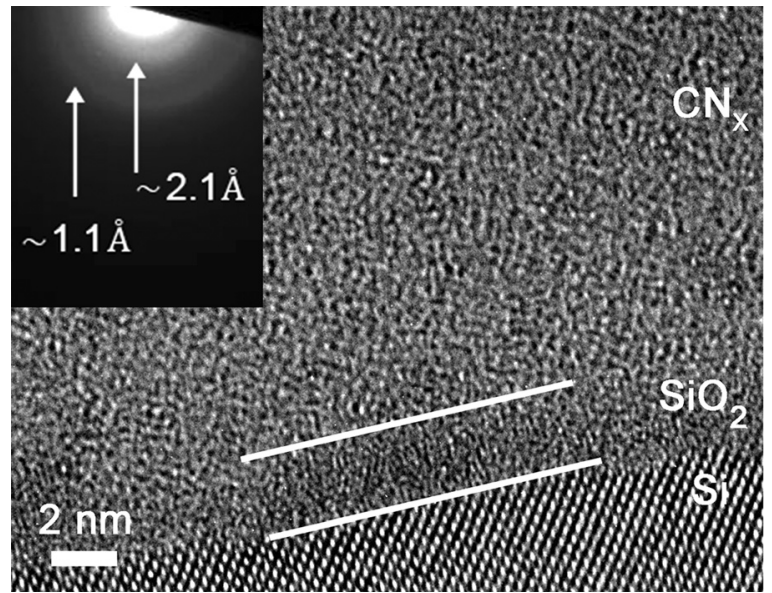

FIG. 6. Cross-sectional HRTEM micrograph and corresponding diffraction pattern (inset) of a $\mathrm{CN}_{\mathrm{x}}$ thin film deposited by MFMS at $\mathrm{V}_{\mathrm{s}}=120 \mathrm{~V}$.

$D$ band that is higher in intensity than the $G$ band. Hence, in this work, the obtained $\mathrm{I}(\mathrm{D}) / \mathrm{I}(\mathrm{G})$ ratios range between $1.54<\mathrm{I}(\mathrm{D}) / \mathrm{I}(\mathrm{G})<1.76$ for all films. However, this ratio does not show particular dependency on $\mathrm{V}_{\mathrm{s}}$. This may be ascribed to rather small changes in the bond configuration, which are further disguised by errors introduced by the peak fit model.

\section{B. Mechanical and tribological film properties}

Figure 8 shows the residual stress, $\sigma$, for all $\mathrm{CN}_{\mathrm{x}}$ films as a function of $\mathrm{V}_{\mathrm{s}}$. All films exhibit compressive residual stresses, which increase with increasing $\mathrm{V}_{\mathrm{s}}$. For films grown with MFMS, $\sigma$ increases linearly from $-0.3 \mathrm{GPa}$ for $\mathrm{V}_{\mathrm{s}}=20 \mathrm{~V}$ to $-4.2 \mathrm{GPa}$ for $\mathrm{V}_{\mathrm{s}}=120 \mathrm{~V}$. The residual stresses are lowest in films grown by HiPIMS. In this case, only a small increase of $\sigma$ from $-0.4 \mathrm{GPa}$ for $\mathrm{V}_{\mathrm{s}}=20 \mathrm{~V}$ to $-1.2 \mathrm{GPa}$ for $\mathrm{V}_{\mathrm{s}}=120 \mathrm{~V}$ is observed. The films deposited in DCMS mode constitute the intermediate case, where $\sigma$ increases to $-2.1 \mathrm{GPa}$ for $\mathrm{V}_{\mathrm{s}}=120 \mathrm{~V}$. The residual stress levels are covarying with the Ar concentration in the $\mathrm{CN}_{\mathrm{x}}$ films [see Figs. 3(c) and 8]; all deposition techniques yield an increase of the Ar content in the films corresponding to an increase in $\sigma$. Thus, we reason that Ar intercalation in the films adds to compressive stresses. However, the higher $\sigma$ values encountered at higher $\mathrm{V}_{\mathrm{s}}$ are primarily ascribed to a decreased void formation and suppressed columnar growth, ${ }^{44}$ due to an increased energy of the incident ions, resulting in forward sputtering. ${ }^{44}$ The $\sigma$ induced by the different deposition techniques is primarily related to the amount and charge of the generated ions in the corresponding plasmas together with the different bias duty cycles.

The hardness, $\mathrm{H}$, and reduced elastic modulus, $\mathrm{E}_{\mathrm{r}}$, of the $\mathrm{CN}_{\mathrm{x}}$ films as a function of $\mathrm{V}_{\mathrm{s}}$ are shown in Figs. 9(a) and 9(b), respectively, and listed in Table $\mathrm{I}$. $\mathrm{H}$ and $\mathrm{E}_{\mathrm{r}}$ increase linearly with increasing $\mathrm{V}_{\mathrm{s}}$ and depend on the deposition mode. Films deposited by MFMS show the strongest dependency on $\mathrm{V}_{\mathrm{s}}$ and additionally the highest values of $\mathrm{H}$ $(24.6 \mathrm{GPa})$ and $\mathrm{E}_{\mathrm{r}}(191.9 \mathrm{GPa})$ at a substrate bias of $120 \mathrm{~V}$. Moreover, these films exhibit higher $H$ and $E_{r}$ at each $V_{s}$ than films deposited by DCMS and HiPIMS.

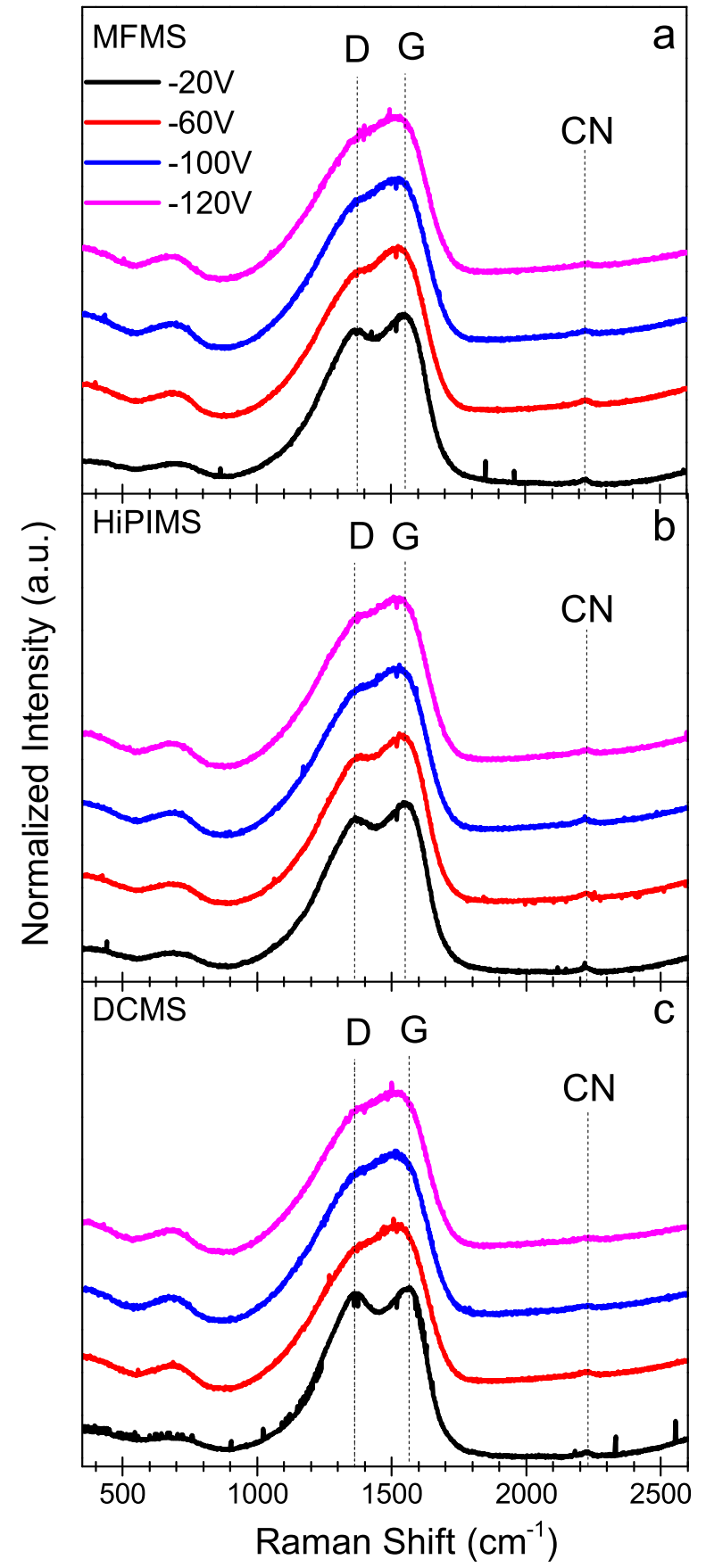

FIG. 7. (Color online) Raman spectra for $\mathrm{CN}_{\mathrm{x}}$ thin films grown with (a) MFMS, (b) HiPIMS, and (c) DCMS from $\mathrm{V}_{\mathrm{s}}=20$ (bottom spectrum) to 60, 100 , and $120 \mathrm{~V}$ (top spectrum).

The mechanical resiliency of the films, extracted as $H / E_{r}$ ratio, expresses the plastic and elastic behavior of materials.

Figure 9(c) shows that films deposited in MFMS and DCMS mode at higher $\mathrm{V}_{\mathrm{s}}$ exhibit a $\mathrm{H} / \mathrm{E}_{\mathrm{r}}$ ratio equal or higher than magnetron sputtered DLC films, ${ }^{17}$ where DLC is considered to belong to the category of very resilient materials. The reduction in porosity (Fig. 2) combined with an increased density [Fig. 3(a)] of the $\mathrm{CN}_{\mathrm{x}}$ films grown by MFMS produces harder films than DCMS and HiPIMS. The ER of the films (Table I) ranges between $73.5 \%$ and $90.7 \%$ and generally increases with increasing $\mathrm{V}_{\mathrm{s}}$. The films deposited in 


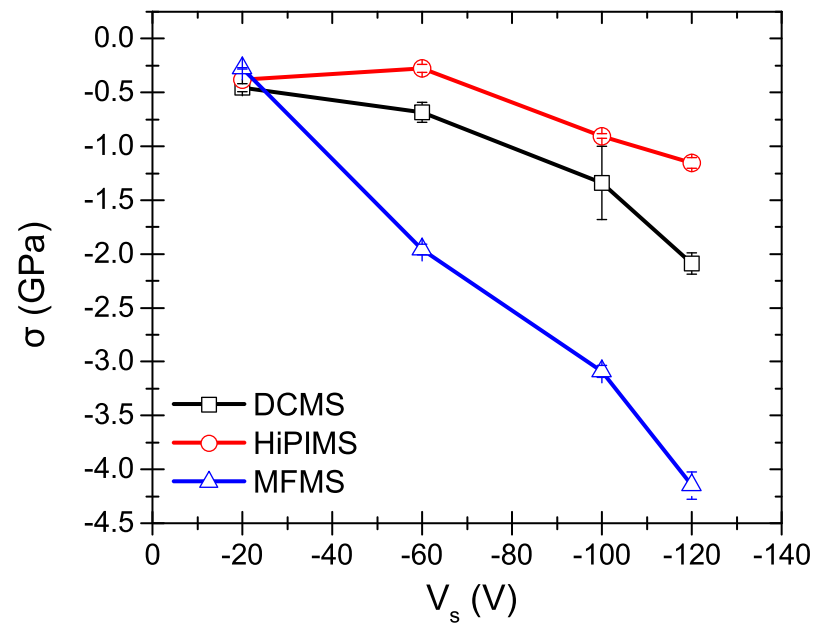

FIG. 8. (Color online) Residual stress of $\mathrm{CN}_{\mathrm{x}}$ thin films deposited in MFMS, HiPIMS, and MFMS mode as a function of $\mathrm{V}_{\mathrm{s}}$.

MFMS and DCMS mode show medium to high ER (see also Ref. 12 for comparison). The highest ER of $90.7 \%$ was extracted for a $\mathrm{CN}_{\mathrm{x}}$ film deposited by MFMS at $\mathrm{V}_{\mathrm{s}}=120 \mathrm{~V}$ and is thus within the ER ranges of FL- $\mathrm{CN}_{\mathrm{x}}$ films. The ER of films deposited in HiPIMS mode shows no dependency on $\mathrm{V}_{\mathrm{s}}$. The increased ER of the films deposited in MFMS and DCMS modes at higher $\mathrm{V}_{\mathrm{s}}$ is ascribed to increased amount of $s p^{2}$-hybridized configurations (cf. Fig. 5).

The tribological performance of the films is presented in Fig. 10. In Fig. 10(a), the average steady-state friction coefficient, $\mu$, of the films as a function of $\mathrm{V}_{\mathrm{s}}$, is shown. The data were extracted after the 6th cycle when the surface was stabilized and most asperities have been smoothened. For all films, the steady-state friction ranges between 0.053 $( \pm 0.001) \leq \mu \leq 0.065( \pm 0.001)$ (the errors refer to the dispersion of the values from the 6th to 31st cycle of the same wear test for each film). The friction does not show a dependency on $\mathrm{V}_{\mathrm{s}}$ or the sputter mode. The dispersion of the extracted friction coefficient values is influenced by the surface roughness of the films, the variation between consecutive tests of the same film, possible contamination of the tip or the film surface, and the tip shape, as well as embedded particles. ${ }^{45}$ These parameters may affect the values of the tangential frictional force and consequently the values of the friction coefficient. The thin error bars in Fig. 10(a) indicate the dispersion of the friction coefficient that has been extracted from different wear tests on the same film. The relatively high dispersion between the wear tests of the same films indicates that the characteristics of the chosen area for the wear test influence the friction. Figure 10(b) shows the wear coefficient, $k$ derived from the last cycle of each measurement as a function of the $\mathrm{V}_{\mathrm{s}}$. The wear coefficient decreases with increasing $\mathrm{V}_{\mathrm{s}}$ for all deposition techniques. The films deposited by MFMS show generally lower $k$ than films grown by HiPIMS and DCMS. Specifically, the film deposited by MFMS at $\mathrm{V}_{\mathrm{s}}=120 \mathrm{~V}$ shows no wear. Films deposited by HiPIMS show higher wear than MFMS and DCMS. For the $\mathrm{CN}_{\mathrm{x}}$ films deposited by HiPIMS, the lowest value of $7.46 \times 10^{-5} \mathrm{~mm}^{3} / \mathrm{Nm}$ was achieved at

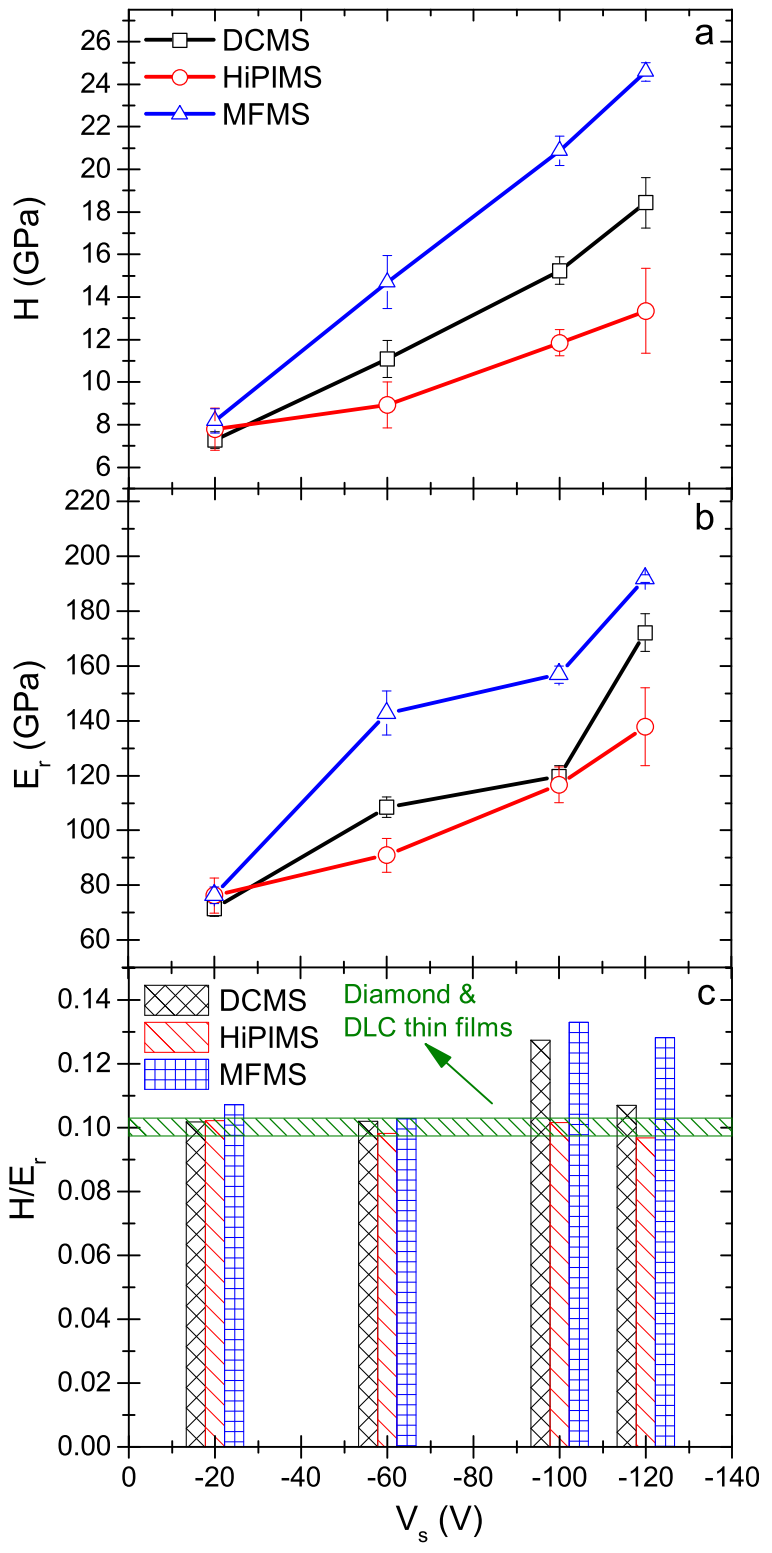

FIG. 9. (Color online) (a) Hardness, (b) reduced elastic modulus, and (c) $\mathrm{H} / \mathrm{E}_{\mathrm{r}}$ ratio of $\mathrm{CN}_{\mathrm{x}}$ thin films deposited in MFMS, HiPIMS, and MFMS mode as a function of $V_{\mathrm{s}}$. The $\mathrm{H} / \mathrm{E}_{\mathrm{r}}$ ratio of diamond and DLC thin films is also denoted (Ref. 17).

$\mathrm{V}_{\mathrm{s}}=120 \mathrm{~V}$. Films deposited in DCMS mode show the lowest wear of $2.4 \times 10^{-6} \mathrm{~mm}^{3} / \mathrm{Nm}$ also at $\mathrm{V}_{\mathrm{s}}=120 \mathrm{~V}$. The wear correlates with the hardness of the films. This agrees with Archard's observations for wear and the formula stated by Holmberg et al., ${ }^{46}$ where the worn volume is inversely proportional with the hardness of the material,

$$
V=\frac{k}{H} L F_{n} .
$$

Here, $L$ is the sliding distance, $F_{n}$ is the applied normal force, and $k$ is the wear coefficient. Moreover, high elastic recovery and thus high amounts of $s p^{2}$-hybridized states in the $\mathrm{CN}_{\mathrm{x}}$ films as observed for $\mathrm{CN}_{\mathrm{x}}$ films grown by MFMS at $\mathrm{V}_{\mathrm{s}}=100$ and $120 \mathrm{~V}$ appears to contribute to low wear. Therefore, the wear rate of the $\mathrm{CN}_{\mathrm{x}}$ films seems to depend 


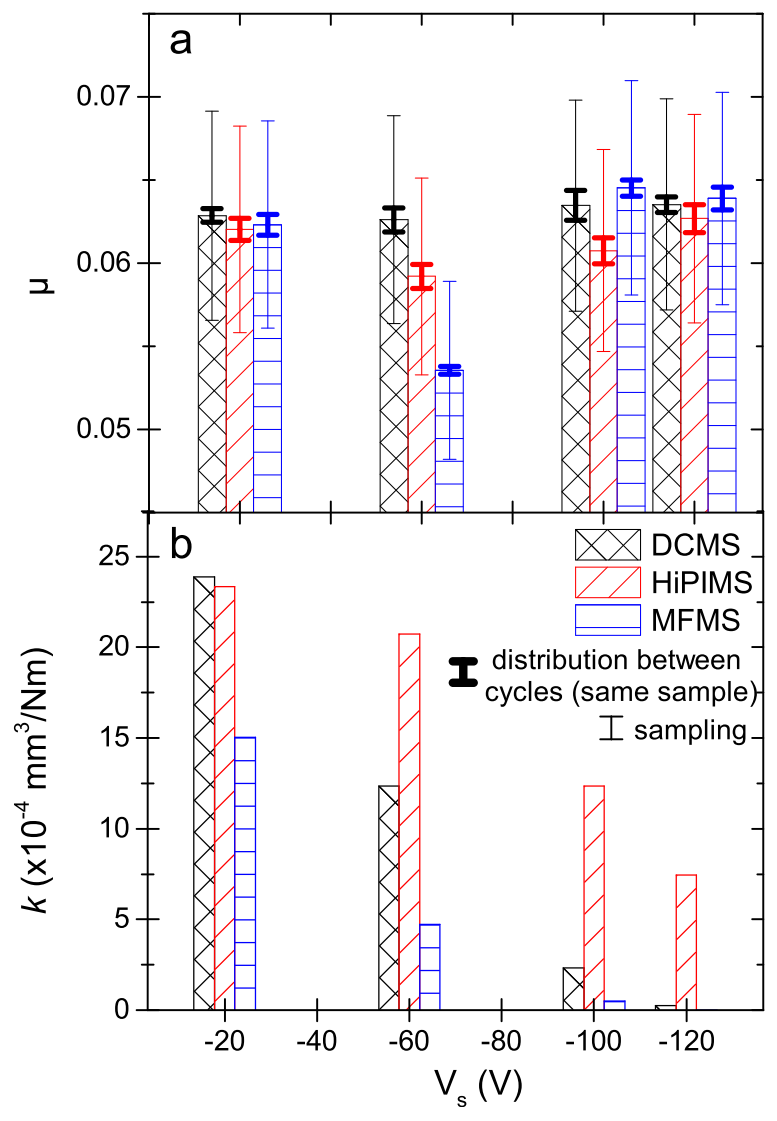

FIG. 10. (Color online) (a) Average steady-state friction coefficient extracted after the 6th cycle of the reciprocal wear test and (b) wear coefficient, derived after 31 cycles of the reciprocal wear test as a function of $\mathrm{V}_{\mathrm{s}}$ for MFMS, HiPIMS, and DCMS. The bold error bars indicate spread of the friction coefficient between different cycles of the same wear test, while the thin error bars indicate the spread between different wear tests of the same $\mathrm{CN}_{\mathrm{x}}$ film.

on a combination of high hardness and high elastic recovery. This combination of film properties is likely to advance an abrasive wear mechanism for these films. Adhesive wear was not observed for the relatively high contact pressure of 8.5 GPa that has been applied.

\section{SUMMARY AND CONCLUSIONS}

Amorphous $\mathrm{CN}_{\mathrm{x}}$ thin films of high mechanical resiliency can be deposited at a low substrate temperature of $150{ }^{\circ} \mathrm{C}$ using MFMS, HiPIMS, and DCMS techniques, provided that a substrate bias is applied to obtain nonporous materials. For MFMS, the bias can be as low as $60 \mathrm{~V}$, whereas for HiPIMS and DCMS, a bias of 120 and $100 \mathrm{~V}$ is required, respectively. DCMS was confirmed to be a technique to produce $\mathrm{CN}_{\mathrm{x}}$ films of high hardness, ${ }^{12}$ while HiPIMS yields the least stressed films and a moderate hardness $\leq 14 \mathrm{GPa}$. C-based films and especially $\mathrm{CN}_{\mathrm{x}}$ films with low stresses are desirable for applications where adhesion is essential, such as steel sliding or rolling components. The $\mathrm{CN}_{\mathrm{x}}$ films grown by MFMS are characterized by high hardness $(\sim 25 \mathrm{GPa})$ and compressive stresses up to $\sim 4.2 \mathrm{GPa}$. The corresponding elastic recovery of the films reaches $90 \%$, resembling the elastic recovery of fullerenelike $\mathrm{CN}_{\mathrm{x}}$ films. ${ }^{23}$ Low friction coefficients between 0.053 and 0.065 were recorded for all studied $\mathrm{CN}_{\mathrm{x}}$ films. Thus, the different deposition techniques and conditions are not detrimental for the $\mathrm{CN}_{\mathrm{x}}$ friction coefficient. On the other hand, high wear resistance can be directly related to homogeneous, dense, and hard $\mathrm{CN}_{\mathrm{x}}$ films with high elastic recovery. The high elasticity of these films is promoted by $s p^{2}$-hybridized $\mathrm{C}$ bonds that increase in abundance as $\mathrm{V}_{\mathrm{s}}$ increases. These resilient a- $\mathrm{CN}_{\mathrm{x}}$ thin films pose the advantages of both hard and soft films and can potentially be used in application requiring low friction and very good wear resistance.

\section{ACKNOWLEDGMENTS}

VINN Excellence Center Functional Nanoscale Materials (FunMat) and Swedish Foundation for Strategic Research through the Synergy Grant FUNCASE are acknowledged. The authors also thank the staff at the Tandem Laboratory, Uppsala University, for the support during the ERDA measurement. The authors also acknowledge the Knut and Alice Wallenberg Foundation (KAW) for their generous contribution to Linköping's electron microscopy laboratory. S.S. acknowledges the support by the Carl Tryggers Foundation for Scientific Research.

${ }^{1}$ A. C. Ferrari, Surf. Coat. Technol. 180-181, 190 (2004).

${ }^{2}$ J. Robertson, Tribol. Int. 36, 405 (2003).

${ }^{3}$ A. Koistinen, S. S. Santavirta, H. Kröger, and R. Lappalainen, Biomaterials 26, 5687 (2005).

${ }^{4}$ B. Kleinsorge, A. C. Ferrari, J. Robertson, W. I. Milne, S. Waidmann, and S. Hearne, Diamond Relat. Mater. 9, 643 (2000).

${ }^{5}$ I. Shimoyama, G. Wu, T. Sekiguchi, and Y. Baba, J. Electron Spectrosc. 114-116, 841 (2001).

${ }^{6}$ J. Neidhardt, Z. Czigány, I. F. Brunell, and L. Hultman, J. Appl. Phys. 93, 3002 (2003).

${ }^{7}$ A. A. Voevodin, J. G. Jones, T. C. Back, J. S. Zabinski, V. E. Strel'nitzki, and I. I. Aksenov, Surf. Coat. Technol. 197, 116 (2005).

${ }^{8}$ N. Hellgren, M. P. Johansson, E. Broitman, P. Sandström, L. Hultman, and J. E. Sundgren, Thin Solid Films 382, 146 (2001).

${ }^{9}$ S. Schmidt, Z. Czigány, G. Greczynski, J. Jensen, and L. Hultman, J. Appl. Phys. 112, 013305 (2012).

${ }^{10}$ G. K. Gueorguiev, J. Neidhardt, S. Stafström, and L. Hultman, Chem. Phys. Lett. 410, 228 (2005).

${ }^{11}$ N. Hellgren, M. Johansson, E. Broitman, L. Hultman, and J.-E. Sundgren, Phys. Rev. B 59, 5162 (1999).

${ }^{12}$ S. Louring, N. D. Madsen, A. N. Berthelsen, B. H. Christensen, K. P. Almtoft, L. P. Nielsen, and J. Bøttiger, Thin Solid Films 536, 25 (2013).

${ }^{13}$ H. K. D. H. Bhadeshia, Prog. Mater. Sci. 57, 268 (2012).

${ }^{14}$ J. M. Ripalda, E. Román, L. Galán, I. Montero, S. Lizzit, A. Baraldi, G. Comelli, G. Paolucci, and A. Goldoni, J. Chem. Phys. 118, 3748 (2003).

${ }^{15}$ A. C. Ferrari, S. E. Rodil, and J. Robertson, Phys. Rev. B 67, 155306 (2003).

${ }^{16}$ J. Neidhardt, H. Högberg, and L. Hultman, Thin Solid Films 478, 34 (2005).

${ }^{17}$ C. A. Charitidis, Int. J. Refract. Met. Hard Mater. 28, 51 (2010).

${ }^{18}$ L. Hultman, J. Neidhardt, N. Hellgren, H. Sjöström, and J.-E. Sundgren, MRS Bull. 28, 194 (2003).

${ }^{19}$ R. Kaltofen, T. Sebald, and G. Weise, Thin Solid Films 290-291, 112 (1996).

${ }^{20}$ C. Charitidis and S. Logothetidis, Thin Solid Films 482, 120 (2005).

${ }^{21}$ C. A. Charitidis and S. Logothetidis, Diamond Relat. Mater. 14, 98 (2005).

${ }^{22}$ S. Schmidt, Z. Czigány, G. Greczynski, J. Jensen, and L. Hultman, J. Vac. Sci. Technol. A 31, 011503 (2013).

${ }^{23}$ J. Neidhardt, L. Hultman, E. Broitman, T. W. Scharf, and I. L. Singer, Diamond Relat. Mater. 13, 1882 (2004). 
${ }^{24}$ J. C. Sánchez-López, M. Belin, C. Donnet, C. Quirós, and E. Elizalde, Surf. Coat. Technol. 160, 138 (2002).

${ }^{25}$ F. Zhou, K. Adachi, and K. Kato, Surf. Coat. Technol. 200, 4909 (2006).

${ }^{26}$ A. Laskarakis, S. Logothetidis, C. Charitidis, M. Gioti, and Y. Panayiotatos, Diamond Relat. Mater. 10, 1179 (2001).

${ }^{27}$ P. Wang, M. Hirose, Y. Suzuki, and K. Adachi, Surf. Coat. Technol. 221, 163 (2013).

${ }^{28}$ R. M. Langford and A. K. Petford-Long, J. Vac. Sci. Technol. A 19, 2186 (2001).

${ }^{29}$ H. J. Whitlow, G. Possnert, and C. S. Petersson, Nucl. Instrum. Methods B 27, 448 (1987).

${ }^{30}$ J. Jensen, D. Martin, A. Surpi, and T. Kubart, Nucl. Instrum. Methods B 268, 1893 (2010).

${ }^{31}$ M. S. Janson, Internal Report, Uppsala University (2004).

${ }^{32}$ M. A. Hopcroft, W. D. Nix, and T. W. Kenny, J. Microelectromech. Syst. 19, 229 (2010).

${ }^{33}$ G. C. Stoney, P. R. Soc. Lond. A-Conta 82, 172 (1909).

${ }^{34}$ W. C. Oliver and G. M. Pharr, J. Mater. Res. 7, 1564 (1992).

${ }^{35} \mathrm{G}$. Greczynski and L. Hultman, Vacuum 84, 1159 (2010).
${ }^{36}$ J. Neidhardt, L. Hultman, and Z. Czigány, Carbon 42, 2729 (2004).

${ }^{37}$ J. Schwan, S. Ulrich, T. Theel, H. Roth, H. Ehrhardt, P. Becker, and S. R. P. Silva, J. Appl. Phys. 82, 6024 (1997).

${ }^{38}$ Y.-S. Jin, T. Shibata, Y. Matsuda, and H. Fujiyama, Thin Solid Films 345, 18 (1999).

${ }^{39}$ N. Hellgren, J. Guo, Y. Luo, C. Såthe, A. Agui, S. Kashtanov, J. Nordgren, H. Ågren, and J. E. Sundgren, Thin Solid Films 471, 19 (2005).

${ }^{40}$ S. S. Roy, R. McCann, P. Papakonstantinou, P. Maguire, and J. A. McLaughlin, Thin Solid Films 482, 145 (2005).

${ }^{41}$ N. Hellgren, K. Macák, E. Broitman, M. P. Johansson, L. Hultman, and J. Sundgren, J. Appl. Phys. 88, 524 (2000).

${ }^{42}$ S. Souto, M. Pickholz, M. dos Santos, and F. Alvarez, Phys. Rev. B 57, 2536 (1998).

${ }^{43}$ R. Gago, J. Neidhardt, M. Vinnichenko, U. Kreissig, Z. Czigány, A. Kolitsch, L. Hultman, and W. Möller, Thin Solid Films 483, 89 (2005).

${ }^{44}$ H. Windischmann, CRC Crit. Rev. Solid State 17, 547 (1992).

${ }^{45}$ B. Bhushan, Wear 259, 1507 (2005).

${ }^{46}$ K. Holmberg, A. Matthews, and H. Ronkainen, Tribol. Int. 31, 107 (1998). 